\title{
Ueber Extractbereitung.
}

(Briefliche Notiz von Ilerrn Apotheker Pfeffer in St. Petersburg.)

Im letzten Winter hatte ich 3 Unzen Kamillenöl über $40 \mathrm{Pfd}$. Kamillenblumen abgezogen, weil es seine blaue Farbe verloren hatte.

1)ie Kamillen liess ich auspressen, die Flüssigkeit absclzen und stellte dic $140 \mathrm{Pld}$. klare Flüssigkeit in einem Topfe in eine Temperatur von -10 bis $12^{\circ} \mathrm{R}$. Nach 9 Stunden war das Wasser gefroren und etwa 50 Plund einer syrupsdicken Flüssigkeit zurückgeblichen, welche im Dampflade abgedunstet ein schönes klares und kräftiges Extract gaben. $\Lambda$ uf ähnliche Weise erhielt ich aus trockner Löwenzahnwurzel ein schönes Extract. Auch Herr Krafft hat nach dieser Methode Versuche angestellt.

\section{Zusatz von Dr. L. F. Bley.}

Bereits im Jahre 1830 veroffentlichte G. Busch in Blekede im 33. Bande dieses Archivs S. 89. cinen Versuch, die Concentration der Extractbriihe durch Frostkälte zu beschleunigen. Er bemerkt darüber, dass die auf diese Weise dargestellten Extractc von hellerer Farbe, als die auf gewöhnliche Weise bereiteten Extracte sind und dass sie im hohen Grade den eigenthiimlichen Geruch und Geschmack der Pllanzensubstanzen besitzen, aus welchen sie erhalten sind, was Brandes in einer Anmerkung bestatigh hat.

Um über die Beschaffenheit dieser Extracte im Vergleich mit dem auf gewöhnlichem Wege erhaltenen ins Klare zu kommen, liess ich von gleichen Portionen Vegetabilien, als Kamillen und Löwenzahnwurzel Extracte darstellen und einen Theil durch Frostkälte concentriren, während der andere Theil durch Abdunsten in gelinder Wärme inspissirt wurde.

1 Pfd. Kamillen gab auf gewöhnliche Weisc 4 Unzen Extract, mittelst Concentration durch Frost nur $2 \frac{1}{2}$ Enze. 1 Pfd. Löwenzahnwurzeln gab nach ersterer Weise $6 \frac{1}{2}$ L'nze Extract, mittelst Frostkialte $1 \frac{1}{2}$ Lnzen weniger.

Dic gefrorene Masse des Kamillenextracts enthielt aber 
Meyer, über eine Verunreinigung des Jods mit Cyanjod. 29

ätherisches Oel, wie der Geruch bewies, so wic pflanzensaure Salzc, letzlere waren auch in dem gefrorenen Theile des Löwenzahnextracts nachzuweisen.

Hiernach möchte wohl die Concentration der Extracte in ihrer Wirksamkeit abgeänderte Extracte geben und diese Methode ohne gesetzliche Vorschrift zur Bercitung der Extracte nicht in Anwendung gebracht werden dürfen.

Ueber interessante Gäbrungsproducte, welche bei Darstellung des Extractum Taraxaci mittelst Frosthälte und bei der weitern Abdunstung erhalten wurden, wird spätcr die Rede sein.

\section{leber eine Verunreinigung des Jods mit Cyanjod ;

\author{
von \\ F. Meyer in Hannover.
}

Von einer wegen mancher Eigenthümlichkeiten zur Verfügung gestellten Quantität Jod wurde mir, des von meinem Principale IIcrin B o ss cll bei dessen L'ntersuchung daran gekniupften Interesses wegen, zu näherer und dessen Resultat zugleich bestätigender Untersuchung, ein Theil gegeben.

Es bildete dieses Jod kleine, glänzende Schuppen, zwischen denen sich bei genauerer Beobachtung mit einer Loupe einzelne weisse, farblose, nadelförmige Krystalle deutlich erkennen liessen; es war sehr feucht und besass einen zwar dem Jod ähnlichen, doch nebenbei stark durchdringenden, eigenthümlichon Geruch.

Nachdem dasselbe in einem verschlossenen Glase und einer Temperatur von +12 bis $15^{\circ}$ R. gestanden, sublimirten die erwähnten Krystalle, flüchtiger als das Jod sellsst, im oberen Theile des Gefässes, wobei mehrere nach Vorlauf von 14 Tagen die Länge eines halben Zolls und darüber erreicht hatten. Herr Bossell machte mich auf diese Krystalle wie später auf einen Blausäure-Geruch 